\title{
Cognitive Conflict of IAIN Tulungagung Students with Independent Cognitive Style in Solving Integral Problems
}

\author{
Sutopo $^{1}$, Akbar Sutawidjaja ${ }^{2}$, Cholis Sa'dijah ${ }^{2}$, I Nengah Parta ${ }^{2}$ \\ \{sutopo.1303119@students.um.ac.id ${ }^{1}$, akbarsutawidjaja@um.ac.id ${ }^{2}$, \\ cholis.sadijah.fmipa@um.ac.id ${ }^{3}$, nengah.parta.fmipa@um.ac.id $\left.{ }^{4}\right\}$ \\ Graduate Student of State University of Malang ${ }^{1}$, Department of Mathematics Education, \\ State University of Malang ${ }^{2}$
}

\begin{abstract}
According to Piaget's theory, when students can identify the cognitive conflict of their experience (Piaget uses the term disequilibrium), it can motivate them to try solving the problem. If the existing cognitive structure works well, the students will reach an equilibration process to explain the newly acquired knowledge when they interact to their environment. When existing cognitive structures fail to react to new information, there is cognitive conflict that causes individuals to chase reeculibration through existing cognitive structures. The individual will move up to a higher level of equilibrium development after the accommodation process is carried out. Cognitive conflict is defined as a person's awareness of a mismatch between the cognitive structure possessed and the new information they have received. Hence, it is needed to present the results of a study of the profile of cognitive conflict in mathematics education majors IAIN Tulungagung in this article, that results can be used by teachers to make appropriate improvements to the conceptualization of students.
\end{abstract}

Keywords : cognitive, integral, field independent conflict

\section{Introduction}

In problem solving situations, students are usually faced with challenges and often faced deadlock. Presenting a cognitive conflict intentionally is an attempt to familiarize and provide experience to students on how to deal with an undesirable situation, provide challenges and opportunities for students to strengthen their knowledge and mathematical skills[1].

Research related to conceptual change was conducted by Kang which states that cognitive conflict and situational interest are factors that influence conceptual change[2]. Moody, examines that the mechanism of conceptual change with respect to the size of decimals[3]. The research findings show that to stimulate cognitive conflict is by involving students in practical tasks and providing feedback on contradictions that arise between new evidence and prior thought. It is estimated that the results of student evidence are an important factor in initiating steps towards conflict resolution. Another study is conducted by Kabaca whom study about misconceptions, cognitive conflict and conceptual changes in geometry[4]. The results of this study indicate that cognitive conflict appeared through teaching with mathematical software requires prior knowledge of the research subject. That is why for the next research, the initial 
knowledge or previous knowledge of students was important to be studied in obtaining the characteristics of students' cognitive conflict.

Lee \& Byun, examines the students 'initial knowledge about cognitive conflict and giving implications to teachers, that learning situations are full of conflicts between prior student knowledge and new information learned, teachers might have special opportunities to improve students' learning every day[5]. If a teacher can be better understand students' cognitive conflict features and their impact on learning, the teacher will be able to help students experience constructive cognitive conflict and conceptual change by guiding them to recognize contradictions, feel interested, maintain relevant anxiety, reflect on the situation, and manage knowledge initially .

In term of learning situations, cognitive conflict can take many forms, such as it appears naturally when someone's hypotheses is wrong after either the results are contradictory or may be provoked by teachers and other students who express their opposite opinion. According to Kwon \& Lee, cognitive conflict is defined as a conflict between cognitive structures (i.e. organized structures of knowledge in the brain) and the environment (for example, an experiment, demonstration, peer opinions, books, or others), or conflicts between conceptions in structures cognitive[6]. There is step when a child finally realizes the fact that he holds two conflicting views about the situation and it is totally wrong, this step is called by cognitive conflict or disequilibrium. Moody, argues that cognitive conflict is a term used to describe the tension created when new evidence is recognized by students and it is contradiction with their previous knowledge[3]. The emotional reactions raised by students in cognitive conflict situations are doubt, confusion, uncertainty, anxiety, tension and always looking back[6].

From the description above, it is necessary to conduct a study of describing cognitive conflict experienced by students when solving problems in a wide area by using integrals. The results of this study are certainly useful for teachers as a strategies for embedding students' concepts so that students' comprehension of the area is getting better.

\section{Literature Review}

Three kinds of instructional strategies can summarise many of the instructional efforts made to promote concep- tual change: (a) the induction of cognitive conflict through anomalous data; (b) the use of analogies to guide students' change; and (c) cooperative and shared learning to promote collective discussion of ideas[7]. According to Kwon \& Lee, cognitive conflict is defined as a conflict between cognitive structures (i.e. organized structures of knowledge in the brain) and the environment (for example, an experiment, demonstration, peer opinions, books, or others), or conflicts between conceptions in structures cognitive. There is step when a child finally realizes the fact that he holds two conflicting views about the situation and it is totally wrong, this step is called by cognitive conflict or disequilibrium[6]. Moody, argues that cognitive conflict is a term used to describe the tension created when new evidence is recognized by students and it is contradiction with their previous knowledge[3]. The emotional reactions raised by students in cognitive conflict situations are doubt, confusion, uncertainty, anxiety, tension and always looking back[6].

According to Lee \& Kwon, cognitive conflict is developed to explain the situation when a student is faced with an anomalous situation neither suit him nor his preconceptions in learning[6]. Anomalous data plays an important role in learning science and has been used extensively in teaching to promote conceptual change. The main purpose of teaching conflict in teaching mathematics is to help students for reflecting their current mathematical understanding, confronting contradictions that arise in situations where some of these understandings are no longer appropriate, and recognizing the importance (need) of modifying the comprehension to 
solve different problems[1]. This model has three stages: the initial stage, the conflict stage, and the resolution stage.

The initial stage is the stage before cognitive conflict happen and it includes a pre-existing process of belief / conception and accepting the anomalous situation as original (that is, the results of experiments obtained by a teacher). In this model, the process or stage of cognitive conflict is defined after students (1) recognizing an anomalous situation, (2) expressing interest or anxiety in overcoming cognitive conflict, and (3) engage in cognitive reassessment. In case, a student acknowledges that the situation is strange with his conception, he must be interested and / or anxious about it. After this stage, students will assess the cognitive conflict situation to complete or just stop it[5].

In situations of cognitive conflict, students will use their cognitive abilities in order to find justification, confirmation or verification of their opinions. It means that the cognitive abilities have the opportunity to be empowered, refreshed, or strengthened, especially if the students are still trying. For example students will use their memory, their understanding of mathematical concepts or their experiences to make the right decisions. In situations of cognitive conflict, students can obtain clarity from their environment, including from teachers or students who are smarter (scaffolding). In other words, cognitive conflict that exists in someone who responds appropriately or positively can refresh and empower the cognitive abilities students have.

In problem solving situations, students are usually faced with challenges and often faced deadlock. Presenting a cognitive conflict intentionally is an attempt to familiarize and provide experience to students on how to deal with an undesirable situation, provide challenges and opportunities for students to strengthen their knowledge and mathematical skills[1].

Thus, the meaning of cognitive conflict in this article is as a one's awareness of a mismatch between the cognitive structure possessed and the new information received. Conceptual change models suggest creating dissatisfaction in a student's mind with their alternative conceptions (in this paper, called cognitive conflict), followed by strengthening the status of the preferred scientific conception[8].

Positive and negative aspects of the impact of cognitive conflict on learning affect researchers' and teachers' positions toward using it as a tool to promote learning[9]. Cognitive conflict is an individual's awareness of contradictory pieces of information affecting a notion in that individual's cognitive structure. Cognitive conflict occurs when an individual cannot apply his/her existing concepts to solve a problem, and thus is confronted with a situation that motivates the learning of new concepts[10].

\section{Methods}

The aim of the article is to explain in detail the profile of cognitive conflict in mathematics education students in solving problems in the area by using integrals. The researchers tried to carry out research carefully, detailed and in-depth examination (by exploring) of what was done, thought, written, drawn, pronounced and body movements on the subject when face and solve problems, in order to obtain an overview of the cognitive conflict profile of students in solving integral problems. The research conducted was descriptive research. The approach used in this study was using a qualitative approach with a type of descriptive-explorative research. The subjects of research were the fourth semester students of mathematics education who had received the subject of differential calculus and integral calculus.

\section{Results and Discussion}


This section presents an explanation and analysis of data related to cognitive conflict of students majoring in mathematics education in solving broad problems using integrals. Students who become the subject of research are 2 students, the results are as follows. Determine the area limited by $\mathrm{y}=2 \mathrm{x}$ and the $\mathrm{x}$ axis between $\mathrm{x}=-2$ and $\mathrm{x}=2$

Cognitive conflict that arises when the subject completes the area is an illustration of the mismatch between the cognitive structures a person has with new information he received. The cognitive conflict that arises when the subject completes the area in the first way, among others, the calculation of the area equal to zero is contrary to the conception of students, namely the area can be searched using the symmetry theorem and the introduction of the types of functions. According to it, the type of cognitive conflict experienced by the subject is a conflict between conception in cognitive structures and external information sources (the results of their resolution)

Signs of cognitive conflict that arise based on the results of observations and the results of interviews when the subject resolves a wide area problem in the second way including; the subject was silent for a long time and looked surprised at knowing the result of the completion of the area under the $\mathrm{X}$ axis equal to -4 . The response is also indicated by multiplying the results of the final calculation of the area value under the $X$ axis which is -4 . Based on the results of the job analysis and the results of the interview, it was seen that the subject experienced cognitive conflict when the final result of the calculation of the area value was equal to -4 . The conception that the subject has regarding the area both under the $\mathrm{X}$ axis and above the $\mathrm{X}$ axis is positive and the calculation results under the $\mathrm{X}$ axis according to the subject are positive. It means that the results of the area under the $\mathrm{X}$ axis which has a negative value of four are very contradictory to the conception.

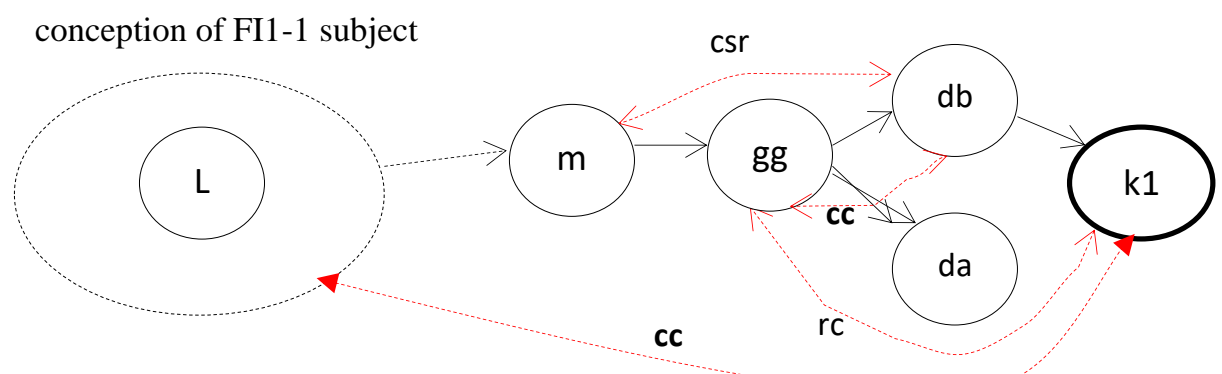

Figure 1. subject cognitive conflict FI1-1 when resolving extensively under the $\mathrm{X}$ axis

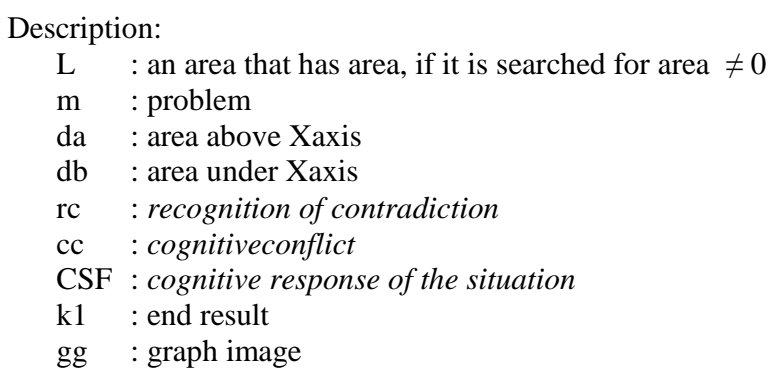

When the subject performs information processing between the broad value of the area obtained and the conception that the subject has then what happens is the emergence of cognitive conflict. Subjects try to absorb new information related to the area obtained and integrate it into 
existing cognitive structures. Based on the results of the interview the subject considers that the problem that has been resolved with the final result of the broad value is negative is not relevant to the conception it has. Things done by the subject include re-interpreting the area defined under the $\mathrm{X}$ axis with the result of a negative area calculation. FI1-1 subject tried to get out of the cognitive conflict experienced but still not able to do so what was done was to continue the work by looking for the area above the $\mathrm{X}$ axis. The following is an illustration of the cognitive conflict experienced by FI1-1 subjects

The cognitive conflict that arises when the subject completes the area under the $\mathrm{X}$ axis, among others, the area value obtained by using integral assistance (the calculation of the area under the $\mathrm{X}$ axis that is negative) is contrary to the concept that students have namely a positive value on the calculation of area. Based on this, the type of cognitive conflict experienced by the subject is a conflict between conception in cognitive structures and external information sources (the results of their resolution). The result of the intended settlement is a solution that works using the symmetry theorem and the type of function, as well as the completion of which the process uses a broad and integral concept of course.

Subject awareness arises after seeing a graphic image that he has painted with the final result of the area obtained is not appropriate. The results of the calculation of the area obtained are equal to zero and the subject believes that it is impossible to have an area equal to zero because based on the graphic image he made there is a wide area. This information is then combined with the subject with initial knowledge on the cognitive structure that he has and then the subject tries to change his cognitive structure based on the information entered. In this case the cognitive balance is needed by the subject in solving the problem of wide area.

Based on the exposure of the work results and the results of FI1-1 subject interviews, the following are presented subject cognitive conflicts when solving questions using the second method with problems determining the area bounded by curves, $\mathrm{X}$ axis, lines and. The emergence of the second settlement initiative was carried out by the subject because of dissatisfaction toward the conceptions and distrust of the decision to resolve the first method. On completion in the second way this cognitive conflict occurs when the subject determines the final outcome of the process. The subject does not fill the result of the sum operation because it will produce a zero value like in the first way.

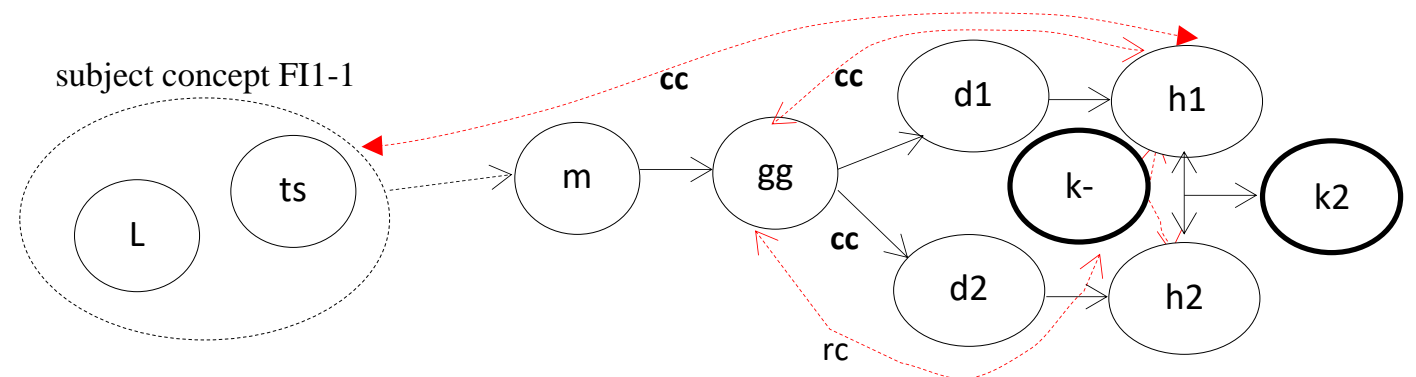

Figure 2. subject cognitive conflict FI1-1 on completion of the second method

Description:

d1 : specifies the estimated curve and above the $\mathrm{X}$ axis as the area sought

d2 : specifies the curve estimated and below the $X$ axis as the area sought

$\mathrm{L} \quad$ : an area that has area, if it is searched for the area $>0$

$\mathrm{m}$ : problem

gg : graph image 


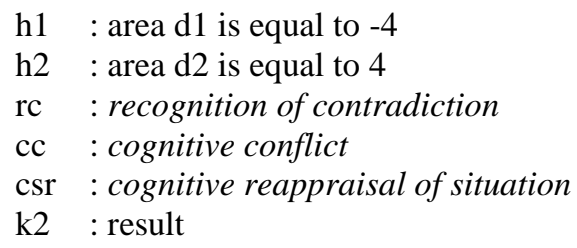

Seeing the results of two different resolutions then FI1-1 tries to make other settlement scrambles in the corner of the answer sheet by directly neutralizing. The area obtained is equal to 0 .

Subjects experience cognitive conflict that is sustainable / protracted can be seen when the subject resolves the problem given in the first way has not been able to get out of the conflict experienced so that the subject is done by trying another way and cognitive conflict occurs again. Based on these exposures in this study the subject experienced cognitive conflict called a sustained cognitive conflict.

The type of cognitive conflict experienced by FI1-1 subjects based on the above explanation is a conflict between conception in cognitive structures and external information sources (the results of their resolution). In this study the moment when the subject resolves a broad problem there is a conception that has, among others, that in solving the broad problem it can be used by using the symmetry theorem and producing a zero value. The other conception that in completing the problem can be solved by looking for the area above the $\mathrm{X}$ axis and below the $\mathrm{X}$ axis. At the time the conception that the subject has shared is used to solve the problem with different results, the subject is aware that he holds two mutual views contradictory so what emerges is cognitive conflict. When the subject sees the final results of the resolution not the same then the situation of cognitive conflict experienced will encourage cognitive abilities in seeking justification, confirmation or verification of his opinion.

Cognitive conflict experienced by the subject occurs naturally after seeing the results of his work (the area produced is equal to zero) and not in accordance with his initial knowledge and cognitive conflict in the subject occurs when the subject sees the first, second and counts of the strokes he made has different results. The form of one's consciousness that arises from itself because of the discrepancy between the cognitive structure possessed and the new information received in this study is called auto cognitive conflict. So based on the findings of this study, what is meant by auto cognitive conflict is a form of awareness of someone who emerges from himself because of a discrepancy between the cognitive structure that is possessed and the new information he receives. New information that is intended in this study after the subject has solved a wide area problem and has concluded the desired results. Subject awareness arises after seeing a graphic image that he has painted with the final result of the area obtained. The results of the calculation of the area obtained are equal to zero and the subject believes that it is impossible to have an area equal to zero because based on the graphic image he made there is a wide area. This information is then combined with the subject with initial knowledge on the cognitive structure that he has and then the subject tries to change his cognitive structure based on the information entered. In this case the cognitive balance is needed by the subject in solving the problem of wide area.

Based on exposure to cognitive conflict experienced by the subject in solving the broad problem of the area by using integrals, the subject experiences continuous / protracted cognitive conflict this can be seen when the subject resolves the problem given in the first way has not been able to get out of the conflict experienced so what the subject does is by trying in another way. Based on these exposures in this study the subject was called sustained cognitive conflict. . 
The cognitive conflict that arises when the subject completes the area, among others; first, the calculation of the area is equal to zero contrary to the conception of students, namely the area can be searched using the symmetry theorem and the introduction of the types of functions and second, the area value obtained by using integral assistance (calculation of the area under the $\mathrm{X}$ axis that is negative) contrary to the conceptions that students have in the calculation of the area of positive value. The type of cognitive conflict experienced by FI1-1 subjects in this study is the conflict between conception (generated by $\mathrm{c} 1$ ) and conception (generated by c2), conflict between conception (c1) and the results of the solution described by $\mathrm{c} 2$, and conflict between conception (c2 ) with the results of the settlement described by $\mathrm{c} 1$. The result of the intended settlement is a solution that works using the symmetry theorem and the type of function, as well as the completion of which the process uses a broad and integral concept of course.

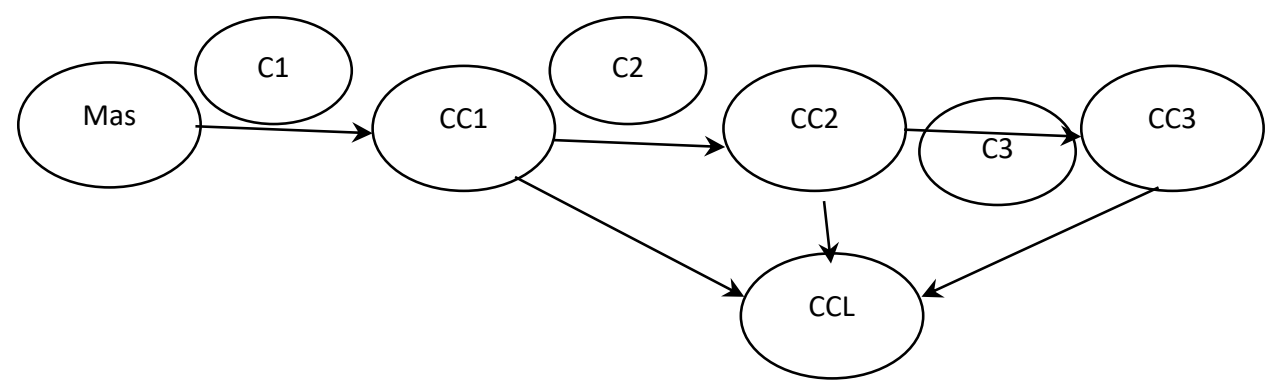

Figure 3. Cognitive conflict that occurs onFI1-1 subject

Mas= problem, $\mathrm{CC} 1,2,3=$ cognitive conflict to 1,2 , and 3, $\mathrm{CCL}=$ Advanced cognitive conflict,

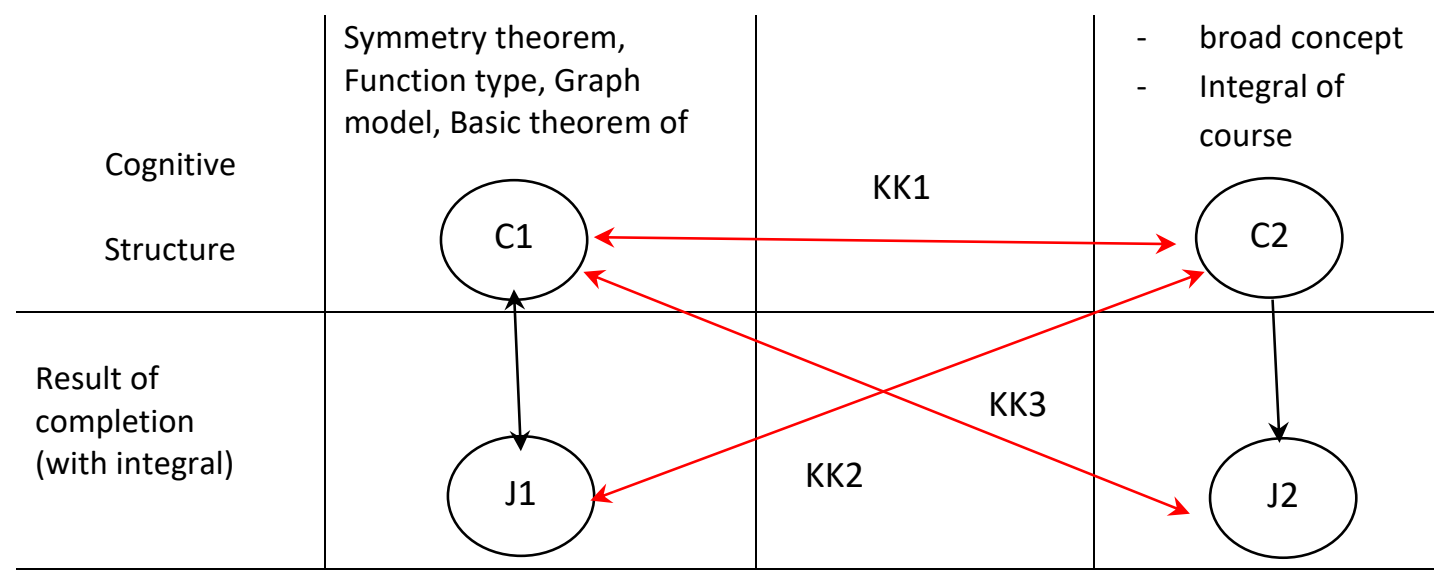

Figure 3. types of cognitive conflict on the subject FI1-1

\section{Conclusion}


Cognitive conflict in the article is as a one's awareness of a mismatch between the cognitive structure possessed and the new information received. There are four psychological constructs of cognitive conflict: recognition of anomalies, interests, anxieties, and reassessment of situations of cognitive conflict. Cognitive conflict has a constructive, destructive or potential form. It is strongly related to how students are in cognitive conflict. By examining signs of cognitive conflict, we can see the potential happen for cognitive conflict.

If a teacher tries to use anomalous phenomena to encourage conceptual change, he will use the model of cognitive conflict process to anticipate how students might be in cognitive conflict. It can help teachers not to let students are in conflict. Cognitive conflict can occur either naturally or due to interference.

\section{References}

[1] A. J. Stylianides and G. J. Stylianides, “ C OGNITIVE CONFLICT' AS A MECHANISM FOR SUPPORTING DEVELOPMENTAL PROGRESSIONS IN STUDENTS ' KNOWLEDGE ABOUT PROOF 1," ICME-11, vol. 11, pp. 1-11, 2008.

[2] H. Kang, L. C. Scharmann, S. Kang, and T. Noh, "Cognitive conflict and situational interest as factors influencing conceptual change," Int. J. Environ. Sci. Educ., vol. 5, no. 4, pp. 383-405, 2010.

[3] B. Moody, "Connecting the Points : Cognitive Conflict and Decimal Magnitude," Proc. 33rd Annu. Conf. Math. Educ. Res. Gr. Australas., pp. 422-429, 2008.

[4] T. Kabaca, "Misconception, cognitive conflict and conceptual changes in geometry: a case study with pre-service teachers Zekeriya KARADAG Muharrem AKTUMEN," Mevlana Int. J. Educ., vol. 1, no. 2, pp. 44-55, 2011.

[5] G. Lee and T. Byun, "An Explanation for the Difficulty of Leading Conceptual Change Using a Counterintuitive Demonstration : The Relationship Between Cognitive Conflict and Responses," Res Sci Educ, vol. 42, pp. 943-965, 2012.

[6] G. Lee, J. Kwon, S. Park, J. Kim, H. Kwon, and H. Park, "Development of an Instrument for Measuring Cognitive Conflict in Secondary-Level Science Classes,” J. Res. Sci. Teach., vol. 40, no. 6, pp. 585-603, 2003.

[7] M. Limo, "On the cognitive conflict as an instructional strategy for conceptual change : a critical appraisal," Learn. Instr., vol. 11, pp. 357-380, 2001.

[8] G. Lee and J. Yi, "WHERE COGNITIVE CONFLICT ARISES FROM ?: THE STRUCTURE," no. August 2011, pp. 601-623, 2013.

[9] H. Sela, "COPING WITH MATHEMATICAL CONTRADICTIONS WITH," ICME 11, no. July, pp. 1-9, 2008.

[10] T. F. Chow and D. F. Treagust, "An Intervention Study Using Cognitive Conflict to Foster Conceptual Change,” J. Sci. Math. Educ. Southeast Asia, vol. 36, no. 1, pp. 44-64, 2013. 